\title{
Development of behavioral arousal and inhibition in the Swiss-Webster mouse
}

\author{
Z. MICHAEL NAGY, JAMES M. MURPHY, and DONALD RAY \\ Bowling Green State University, Bowling Green, Ohio 43403
}

\begin{abstract}
The development of behavioral arousal was examined in mice ranging from 9 to 100 days of age. An inverted U-shaped ontogenetic activity curve was obtained, consistent with past studies of other altricial rodents. However, the peak in the activity curve for the mouse occurred at 13 days of age, at least 2 days earlier than reported for the rat and hamster. The findings are interpreted as indicating that the onset of behavioral inhibitory capacities occur earlier in the mouse and are discussed in relation to development of brainstem arousal and forebrain inhibitory biochemical systems.
\end{abstract}

One of the most dramatic changes observed during ontogeny is the shift from a predominantly "approach" to "withdrawal" mode of responding to low-intensity stimuli (Schneirla, 1965). The initial approach phase insures the exposure of the young organism to a broad range of environmental input which, in turn, guarantees the occurrence of differential reinforcement necessary for later discriminative and reactive specialization. Withdrawal, expressed as the avoidance or cessation of approach to stimuli signaling potential danger or nonreinforcement, emerges at a later developmental period. Thus, in altricial rodents, behavioral arousal to novel stimuli, as measured by general activity (Campbell, Lytle, \& Fibiger, 1969), exploration (Feigley, Parsons, Hamilton, \& Spear, 1972) and spontaneous alternation (Douglas, Peterson, \& Douglas, 1966) is generally greater in young subjects than in adults. Conversely, passive avoidance ability (Feigley, 1974) and general fear reaction to novel stimuli (Candland \& Campbell, 1962) or to stimuli previously paired with noxious stimulation (Brunner, Rossi, \& Roth, 1970) are weaker in juveniles. This shift in response pattern is perhaps most dramatically expressed in the development of spontaneous locomotor activity. Age-related changes in activity of the rat have been found to be an inverted U-shaped function from 10 days of age to adulthood, with the peak occurring between 15 and 20 days of age (Campbell et al., 1969).

The age trend in activity is closely paralleled by developmental changes in brain chemistry and morphology. Initial increases in activity are accompanied by the maturation of adrenergic elements in hindbrain regions thought to mediate behavioral arousal (see Campbell \& Mabry, 1973). A functional relationship between this activity increase and catecholaminergic brainstem and midbrain processes is suggested by the

This research was supported by N. S. F. Research Grant GB-30456. Reprints may be obtained from the first author at: Department of Psychology, Bowling Green State University, Bowling Green, Ohio 43403. demonstration that drugs presumably potentiating or depressing adrenergic transmission are capable of altering behavioral activity in rats at least as young as 10 days of age (Campbell et al., 1969; Campbell \& Mabry, 1973). Between 15 and 20 days of age, the period during which activity begins to decline, rapid increases in cholinergic and serotonergic activity occur in rostral brain areas such as the hippocampus and frontal cortex (see Campbell et al., 1969; Mabry \& Campbell, 1974). The possible role of serotonergic and cholinergic forebrain structures in the mediation of response suppression is suggested by the fact that the initial appearance of activity effects of cholinergic and serotonergic drugs (Campbell et al., 1969; Mabry \& Campbell, 1974) and those resulting from lesions to the hippocampus and frontal cortex (Moorcroft, 1971) coincide with the onset of activity decline of rats between 15 and 20 days of age. That the ontogenetic changes in activity are primarily the result of brain maturation rather than of experience is supported by the finding that the precocial guinea pig, unlike the altricial hamster (or rat), exhibits no postpartum changes in activity level (Campbell \& Mabry, 1972).

The purpose of the present study was to test the generality of the observed ontogenetic changes in spontaneous activity in another altricial rodent, the mouse. A corresponding phase of heightened activity has been reported for mice, although this period has generally been characterized as reflecting hyperreactivity rather than spontaneous hyperactivity (cf. Wahlsten, 1974; Williams \& Scott, 1953). Comparison of central nervous system development for the rat and mouse indicates that maturational processes, though similar, occur earlier in the mouse (cf. Agrawal \& Himwich, 1970; Folch, Casals, Pope, Meath, LeBaron, \& Lees, 1959; Folch-Pi, 1971). Therefore, if the age-related change in activity levels is related to the caudorostral gradient of brain development found in both rats and mice, then one would expect the developmental activity curves for the mouse to be similar to that of the rat, but to also show earlier appearance of the activity peak and subsequent activity decrement. 


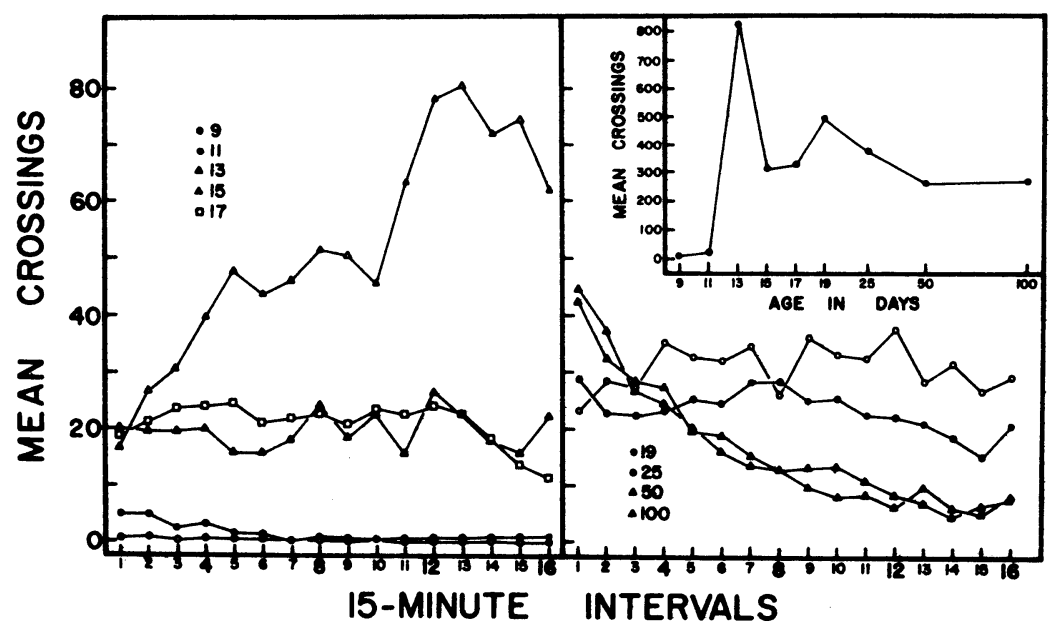

Figure 1. Mean number of crossings as a function of age and 15-min intervals. Mean number of crossings as a function of age are presented in the figure inset.

\section{METHOD}

\section{Subjects}

The subjects were 180 Swiss-Webster mice (Mus musculus), born and reared in $30.4 \times 18 \times 12.8 \mathrm{~cm}$ polyethylene cages with wire-grid tops, wood-chip shavings on the floor, and nesting material provided. All litters were culled to eight pups the day following birth and, except for testing sessions, the mothers remained with the pups until weaning at 28 days of age. The mice were separated according to sex when weaned, and no more than five animals were housed in a cage. The colony room was maintained at $24 \pm 1^{\circ} \mathrm{C}$ and was on a normal 12-h light-dark cycle. Ad-lib food and water were available throughout the study.

\section{Apparatus}

Two sizes of Plexiglas activity monitoring cages were employed. Subjects 25 days of age and younger were tested in $19.4 \times 6.4 \times 9 \mathrm{~cm}$ cages, with grid floors of $1-\mathrm{mm}$ in diam stainless steel rods spaced $4 \mathrm{~mm}$ center to center and extending parallel to the length of the cage. Photocells and red-filtered light sources were spaced $3.4 \mathrm{~cm}$ from each end. The 50 and 100-day-old subjects were tested in larger cages, $26.2 \times 7.6 \times 10 \mathrm{~cm}$, with the grids $6 \mathrm{~mm}$ center to center and running parallel to the width of the cage. Photocells for these larger cages were mounted $5 \mathrm{~cm}$ from each end. All activity cages were enclosed in a humidity-controlled environmental chamber, maintained at $24 \pm 1^{\circ} \mathrm{C}$. The ventilation fan for the chamber furnished a $74 \mathrm{~dB}$ ambient noise level, and two $60-\mathrm{W}$ flourescent lights provided the illumination for the chamber.

Activity counts were registered when the subject crossed alternate photocell beams. Thus, in order to register one activity count, it was necessary for the mouse to at least traverse the distance between photocells. Counts were recorded automatically and printed every $15 \mathrm{~min}$ on apparatus located outside the soundproofed environmental chamber.

\section{Procedure}

Subjects were tested for one 4-h session at 9, 11, 13, 15, 17, 19 , or 25 days of age, according to a modified split-litter design, such that no more than one male and one female from the same litter were assigned to each group. Adult mice of 50 and 100 days of age from the same breeding stock were tested in a similar manner. Subject identification was accomplished by toe-clipping mice 13 days of age and younger and ear-punching older subjects.
At the appropriate age, subjects were removed from the home cage and placed into the activity apparatus. Following the testing session, subjects were replaced in the home cage. The activity cages were cleaned and checked between each session. All sessions were conducted between 0800 and $1700 \mathrm{~h}$ during the normal 12-h light cycle. Except for normal maintenance procedures, the mice were not disturbed or handled other than during the testing sessions.

\section{RESULTS AND DISCUSSION}

Mean number of crossings as a function of age and 15-min intervals appears in Figure 1. A three-way analysis of variance with one repeated measure was conducted on the data with the factors being age, sex, and 15-min intervals. A highly reliable age trend in total crossings during the 4-h session $[F(8,162)=16.27, p<.0005]$, presented in the figure inset, is in general agreement with past findings for the rat (Campbell et al., 1969; Fibiger et al., 1970; Mabry \& Campbell, 1974; Moorcroft, Lytle, \& Campbell, 1971). The dramatic increase in activity between Days 9 and 13 is indicative of the early development of hindbrain arousal systems. Tukey pairwise comparisons between the age means revealed that 9-and 11-day-olds were less active than the 13- through 25-day-olds and that the 13-day-olds were more active than subjects at any other age (all ps <.05). In contrast, the decrease in activity after 13 days of age suggests the emergence of forebrain inhibitory mechanisms presumably counteracting the behavioral expression of developing sensorimotor capacities (Campbell et al., 1969; Fibiger et al., 1970; Mabry \& Campbell, 1974).

The form of the developmental activity curve for the mouse closely resembles that found for other altricial rodent species. However, the activity peak for the mouse occurs around 13 days of age, at least 2 days earlier than has been reported for the rat (Campbell et al., 1969; Moorcroft et al., 1971) and hamster (Campbell \& Mabry, 
1972). As a possible behavioral index of the sequential development of adrenergic, serotonergic, and cholinergic brain systems, this difference is consistent with the relatively earlier development of the mouse (Agrawal \& Himwich, 1970; Folch et al., 1959; Folch-Pi, 1971).

Habituation, defined as the "stimulus specific response decrement resulting from repeated or constant exposure to the response eliciting stimulus" (Wyers, Peeke, \& Herz, 1973), has also been used as an index of excitatory-inhibitory balance (Carlton, 1969). As shown in Figure 1, the general increase in the activity of 13-day-olds over trials suggests the absence of habituation at this age. Tests for simple main effects (Kirk, 1968) conducted within the significant Age by Interval interaction $[F(120,2430)=5.19, p<.0005]$ revealed this within-session increase to be significant $[F(15,2430)=11.76, p<.0005]$. The low levels of activity for the 9- and 11-day-olds are presumably due to the comparative lack of sensorimotor and homeostatic development at these ages, where most of the activity occurs within the first hour following removal from the nest. Although not reaching statistical significance, a developmental trend in the within-session activity levels of 15- to 25-day-olds, possibly reflecting the onset of habituation capacity, can be seen in the figure. A relatively constant level of activity was demonstrated by 15-day-olds throughout the session, which was supplanted by an apparent activity decrement during the last hour in 17- and 19-day-olds and during the last $2 \mathrm{~h}$ in 25-day-olds. In the more mature 50- and 100-day-old groups, reliable decreases in activity occurred over the entire 4-h session $[F(15,2430) \geqslant 4.13$, ps $<.0005]$. In view of the fact that 13-day-olds were capable of pronounced activity increases during the session, this subsequent developmental trend was most likely the expression of enhanced habituation capacity rather than fatigue. These data are in agreement with the results of previous studies of habituation in the developing rat in which habituation of a stimulus dependent response (Feigley et al., 1972) and spontaneous open-field activity (Bronstein, Neiman, Wolkoff, \& Levine, 1974) were not found until the latter part of the 3rd postnatal week. Unfortunately, it is not possible to assess interspecies differences in the emergence of habituation on the basis of these data.

In summary, the results of the present study are consistent with interpretations of past findings for other altricial rodents. The demonstration of similar but earlier-occurring sequential changes in activity levels for the mouse further suggests that forebrain inhibitory mechanisms modulating approach and withdrawal modes of responding occur earlier during ontogeny for the mouse than for the rat or hamster.

\section{REFERENCES}

Agrawal, H. C., \& Himwich, W. A. Amino acids, proteins, and monoamines of developing brain. In W. A. Himwich (Ed.) Developmental neurobiology. Springfield, Ili: Thomas, 1970 Pp. 287-310.

Bronstein, P. M., Neiman, H., Wolk off, F. D., \& Levine, M. J. development of habituation in the rat. Animal Learning and Behavior, 1974, 2, 92-96.

Brunner, R. L., Rossi, R. R., \& Roth, T. Age differences in the development of the conditioned emotional response. Psychonomic Science, 1970, 21, 135-136.

Campbell, B. A., Lytle, L. D., \& Fibiger, H. C. Ontogeny of adrenergic arousal and cholinergic inhibitory mechanisms in the rat. Science, $1969,166,637-638$.

Campbell, B. A., \& Mabry, P. D. Ontogeny of behavioral arousal: A comparative study. Journal of Comparative and Physiological Psychology, 1972, 81, 371-379.

Campbell, B. A., \& Mabry, P. D. The role of catecholamines in behavioral arousal during ontogenesis. Psychopharmacologia, $1973,31,253-264$

Candland, D. K., \& Campbell, B. A. Development of fear in the rat as measured by behavior in the open-field. Journal of Comparative and Physiological Psychology, 1962, 55 593-596.

Carlton, P. L. Brain-acetylcholine and inhibition. In J. T. Tapp (Ed.), Reinforcement and behavior. New York: Academic Press, 1969. Pp. 286-327.

Douglas, R. J., Peterson, J. J., \& Douglas, D. The ontogeny of a hippocampus-dependent behavior in two rodent species. Behaviaral Biology, 1973, 8, 27-37.

Feigley, D. A. Effects of scopolamine on activity and passive avoidance learning in rats of different ages. Journal of Comparative and Physiological Psychology, 1974, 87, 26-36.

Feigley, D. A., Parsons, P. J., Hamilton, L。 W., \& Spear, N. E. Development of habituation to novel environments in the rat. Journal of Comparative and Physiological Psy chology, 1972, $79,443-452$.

Fibiger, H. C., Lytle, L. D., \& Campbell, B. A. Cholinergic modulation of adrenergic arousal in the developing rat. Journal of Comparative and Physiological Psychology, 1970, 72, 384-389.

Folch, J., Casals, J., Pope, A., Meath, J. A., LeBaron, F. N., \& Lees, M. Chemistry of myelin development. In S. R. Korey (Ed.), The biology of myelin. New York: Hoeber, 1959. Pp. 122-137.

Folch-Pi, J. Introduction. In R. Paoletti and A. N. Davison (Eds.), Chemistry and brain development. New York: Plenum Press, 1971. Pp. 1-11.

Kirk, R. E. Experimental design: Procedures for the behavioral sciences. Belmont, California: Brooks-Cole, 1968.

Mabry, P. D., \& Campbell, B. A. Ontogeny of serotonergic inhibition of behavioral arousal in the rat. Journal of Comparative and Physiological Psychology, 1974, 86, 193-201.

Moorcroft, W. H. Ontogeny of forebrain inhibition of behavioral arousal in the rat. Brain Research, 1971, 35, 513-522.

Moorcroft, W. H., Lytle, L. D., \& Campbell, B. A. Ontogeny of starvation-induced behavioral arousal in the rat. Journal of Comparative and Physiological Psychology, 1971, 75, 59-67.

Schneirla, T. C. Aspects of stimulation and organization in approach/withdrawal processes underlying vertebrate behavioral development. In $D$. S. Lehrman, $R$. A. Hinde, and E. Shaw (Eds.), Advances in the study of animal behavior. New York: Academic Press, 1965. Pp. 1-74.

Wahlsten, D. A developmental time scale for postnatal changes in brain and behavior of B6D2F mice. Brain Research, 1974, 72, 251-264.

Williams, E., \& Scott, J. P. The development of social behavior patterns in the mouse, in relation to natural periods. Behaviour, 1953, 6, 35-65.

Wyers, E. J., Peeke, H. V. S., \& Herz, M. J. Behavioral habituation in invertebrates. In H. V. S. Peeke and M. J. Herz (Eds.), Habituation: Behavioral studies Vol. 1. New York: Academic Press, 1973. Pp. 1-57.

(Received for publication May 1, 1975.) 